\title{
28 Authority and responsibility when learning mathematics in a technology-enhanced environment
}

\author{
Thomas Lingefjärd \\ University of Gothenburg
}

Sweden

\author{
Jeremy Kilpatrick \\ University of Georgia \\ Athens, Georgia, USA
}

\begin{abstract}
Given an opportunity to use technology to model difficult mathematical problem situations, prospective teachers at the University of Gothenburg reacted by welcoming realistic work done in project teams or by complaining about having to take responsibility for their own learning. Their criticisms of problems as unclear or too open seemed to reflect their discomfort at having to argue for a best solution rather than finding a unique one. The changes in instruction resulted in a transformation of authority in which results from technology were not questioned, suggesting that issues of responsibility and authority need to be made explicit in instruction.
\end{abstract}

\section{Keywords}

Assessment, attitudes, collaborative learning, modeling, teacher education.

\section{Introduction}

Questions concerning the roles of teacher and student when using new technology in the mathematics classroom are relevant to the education of mathematics teachers, since they are entitled to the same sort of teaching in university mathematics that we expect when they teach schoolchildren. In a technologyenhanced course at the University of Gothenburg, prospective teachers were to become active learners, taking full responsibility for their own learning. The $\mathbf{4 0}$ students were in their second year of mathematical studies, preparing to become teachers of mathematics and natural science for Grades 4 to 9 . All had taken courses in linear algebra, number theory, real analysis, Euclidean geometry, 
probability, and statistics. None had apparently had any collaborative experience in solving 'hard' problems or in using mathematical literature to support their arguments.

The mathematical content of the course was designed to give the students insight into how they could solve extended mathematical problems using mathematical modeling, a good background in mathematics, and technology. The software used was mainly The Geometer's Sketchpad (Key Curriculum Press, 1995), PC Logo, Excel (Microsoft, 1995), CurveExpert (Hyams, 1996), and WinStat (Parris, 1996). Theoretical views of mathematical didactics and of mathematical modeling in education were discussed in literature seminars and during course work.

Most of the students had little or no previous experience with the software, so they were encouraged to work in pairs or larger groups. Their written assignments and final examination, however, were expected to be their own. The two instructors' fears that the students might submit duplicate solutions proved unfounded; the majority put their own characteristic thinking into their solutions.

The students worked in a computer lab with all the software described above and with access to the Internet. Their reports consisted partly of paper documents and partly of computer files on a disk. They could communicate with the instructors from home by electronic mail and fax.

\section{Student problem solving}

The Geometer's Sketchpad, Excel, and graphing calculators were introduced through an example or by solving a specific problem. Only about 15 students owned or could borrow a graphing calculator, so the instructors made another 25 calculators available on loan. As the instructors introduced graphing calculators, they also discussed data analysis, regression analysis, and curve fitting. Those students who wanted to do curve fitting on a home computer could download shareware such as CurveExpert and WinStat from the departmental server. This software was not introduced in class; instead, the responsibility for installation and practice was entirely in the students' hands.

As well as literature-seminar discussions of the purpose and value of computers and graphing calculators in mathematics instruction, the students had homework assignments and a take-home final examination. The assignments served partly as instructional material (see Assignment 1) and partly as preparation for the final examination (see Problem 2). These illustrate the types of tasks used in the course.

\section{Assignment 1}

Let $R(1)=1$ and $k \geq 1, k \in N$.

Let $R(k+1)=1+\frac{k}{R(k)}$ and investigate what happens to $R(k=1)$ when $k \rightarrow \infty$.

Provide relevant argumentation to support your findings. 


\section{Problem 2}

A scientist is interested in analyzing the cooling qualities in a new material she is developing and needs a mathematical model to describe this phenomenon. Therefore she boils water in a bowl made of the material and allows the water to cool while she continuously measures the temperature of the water. Her results are shown in the table. The temperature in the room was a constant $68^{\circ} \mathrm{F}$.

(a) Use spreadsheet software to illustrate these data points in a suitable diagram. Translate the temperature values to degrees Celsius.

(b) Analyse the appearance of the diagram in (a) and try to find a mathematical model, e.g., a function, that describes the cooling of the material both during the measured time and afterward.

(c) Use the standard deviation to measure the error between your model function and the data points

Write a report and describe for the scientist what kind of model she should use. Explain why your model is 'the best'.

\begin{tabular}{|cc|}
\hline Time (mins) & Temp ( $\left.{ }^{\circ} \mathrm{F}\right)$ \\
0 & 212 \\
1 & 205 \\
2 & 201 \\
3 & 193 \\
4 & 189 \\
5 & 184 \\
6 & 181 \\
7 & 178 \\
8 & 172 \\
9 & 170 \\
10 & 167 \\
11 & 163 \\
12 & 161 \\
13 & 159 \\
14 & 155 \\
15 & 153 \\
16 & 152 \\
17 & 150 \\
18 & 149 \\
19 & 147 \\
20 & 145 \\
21 & 143 \\
22 & 141 \\
23 & 140 \\
24 & 139 \\
25 & 137 \\
26 & 135 \\
27 & 133 \\
28 & 132 \\
29 & 131 \\
30 & 130 \\
\hline
\end{tabular}

\section{The examination}

The final examination, distributed on a Monday and due the following Friday, consisted of three problems. The students were assessed on their performance in the literature seminars (their oral and written performance), on the homework assignments, and on the final exam. The grade scale was Excellent, Pass, or Fail.

The students' reactions during the course and on the course evaluation form varied considerably. Some students were very positive about studying and working in project teams: "The first course in mathematics I have taken that resembled how you work outside school ...". Others resisted working together, learning from each other, and being responsible for their own learning: "It is not fair that I should be forced to discuss with my classmates and ask them for advice ...". Many students were inexperienced in communicating mathematics: "I don't want to be assessed on my writing skills in mathematics, only on how I do the mathematics...". Most had apparently never been assessed in terms of how they argued for 'the best solution' (or something close) to a mathematical problem. The problems of being responsible for one's own learning have been discussed by, for example, Ekholm (1997) and Povey (1995).

The students criticized some tasks as 'unclear'. The unspoken assumption seemed to be that problems should lead to a definite 'number'. The strongest critiques involved Problem 2 on the final exam, which was criticized for being too 
'open', allowing too many strategies, and so on. Only one of the 40 students recalled Newton's law of cooling, although it is commonly used in the Swedish gymnasium to illustrate a decreasing exponential function.

A major result of the changed instruction was the transformation of authority that took place after the first few weeks. The students became rather uncritical of the results they got from the computer or graphing calculator. In Problem 2, for example, some attempted to find the best value of $r$ (the correlation coefficient) instead of discussing what kind of relation there might be. They simply allowed CurveExpert to generate suitable curve-fitting models, picked the one with the highest value of $r$, and gave it as the answer. When speaking of data points, other students confused the limits of Excel and the mathematical concept of limit: "If we only had a version of Excel with more data points, then we would have been able to give a more accurate answer" (see Assignment 1). Moreover, many students seemed to have replaced the deductive reasoning used in Euclidean geometry by animation and testing hypotheses in geometric construction tasks with The Geometer's Sketchpad.

When one changes teaching and assessment in this way, one is likely to get strong reactions to both. The changes may provoke a discussion of different learning and teaching perspectives, a discussion that should take place in all university courses in mathematics taken by prospective teachers (Romberg, 1993). The awareness of one's own perspective on mathematics, teaching, and learning may thereby become clearer or at least more visible for both students and teachers.

\section{References}

Ekholm, M. (1997). Lärarna måste själva ta ansvar för sin yrkesutbildning. (Teachers must take responsibility for their professional training). Pedagogiska magasinet, 2(1), 52-55.

Hyams, D. (1996). CurveExpert: A curve fitting system for Windows. Clemson, SC: Clemson University.

Key Curriculum Press. (1995). The Geometer's Sketchpad. Berkeley, CA: Author.

Microsoft. (1995). Microsoft Excel. Stockholm, Sweden: Microsoft Scandinavia AB.

Povey, H. (1995) Working for change in teacher education. In L. Burton and B. Jaworski (eds.), Technology in mathematics teaching: $A$ bridge between teaching and learning. Lund, Sweden: Chartwell-Bratt, 135-153.

Parris, R. (1996). WinStat. Exeter, NH: Peanut Software.

Romberg, T. A. (1993). How one comes to know: Models and theories of the learning of mathematics. In M. Niss (ed.), Investigations into assessment in mathematics education: An ICMI study. Dordrecht, Netherlands: Kluwer, 97-111. 